\title{
How does early decompressive craniectomy influence the intracranial volume relationship in traumatic brain injury (TBI) patients?
}

\author{
Piotr Jasielski ${ }^{1}$, Zbigniew Czernicki ${ }^{2}$, Piotr Dąbrowski ${ }^{3}$, Waldemar Koszewski ${ }^{2}$, Rafał Rojkowski ${ }^{4}$ \\ 'Department of Neurosurgery, Bielanski Hospital, Warsaw, Poland \\ ${ }^{2}$ Department of Neurosurgery, II Faculty of Medicine, Medical University of Warsaw, Poland \\ ${ }^{3}$ Department of Neurosurgery, Western Hospital in Grodzisk Mazowiecki, Grodzisk Mazowiecki, Poland \\ ${ }^{4}$ Department of Radiology, Czerniakowski Hospital, Warsaw, Poland
}

\section{ABSTRACT}

Background. Decompressive craniectomy (DC) is a common neurosurgical procedure involving the removal of part of the skull vault combined with subsequent duroplasty. The goal of $D C$ is to produce extra space for the swollen brain and/or to reduce intracranial pressure. In the present study, DC was performed in order to create space for the swollen brain.

Aim of the study:

1. to compare the volume alteration of selected intracranial fluid spaces before and after DC,

2. to evaluate the volume of post-decompressive brain displacement (PDBD) and the largest dimension of oval craniectomy (LDOC), and

3. to assess the early clinical effects of $D C$.

Material and methods. The study group consisted of 45 patients with traumatic brain injury (four females and 41 males, mean age 54.5 years) who underwent DC (not later than five hours after admission to hospital) due to subdural haematomas and/or haemorrhagic brain contusions localised supratentorially and diagnosed by computed tomography (CT). The mortality rate in the study group was $40 \%$. Study calculations were performed using Praezis Plus software by Med Tatra, Zeppelin and Pax Station by Compart Medical Systems. For statistical analysis, IBM SPSS Statistics software was used.

Results. The DC-related additional space was responsible for a statistically significant increase in the volume of preoperatively compressed intracranial fluid spaces. The mean volume of extra space filled by the swollen brain was $42.2 \mathrm{ml} \pm 40.7$. The best early treatment results were achieved in patients under the age of 55 .

Conclusions. DC has limited effectiveness in patients aged over 70 years. In every patient with clamped basal cisterns, a skin incision enabling appropriate LDOC should be planned before surgery. DC should be as large as possible, and the limits of its dimensions should be the limits of anatomical safety.

Key words: traumatic brain injury, decompressive craniectomy, basal cistern volume, brain bulging (Neurol Neurochir Pol 2019; 53 (1): 47-54)

\section{Introduction}

Traumatic brain injury (TBI) is one of the main unresolved health problems around the world. The long-term effects of TBI are a very important challenge for patients because of their suffering and disability. TBI is also a challenge for healthcare systems and involves a huge financial burden both for the families of the sick and for the general population [1].

The number of cases of TBI is high in poorly-developed and moderately-developed countries. The most common 

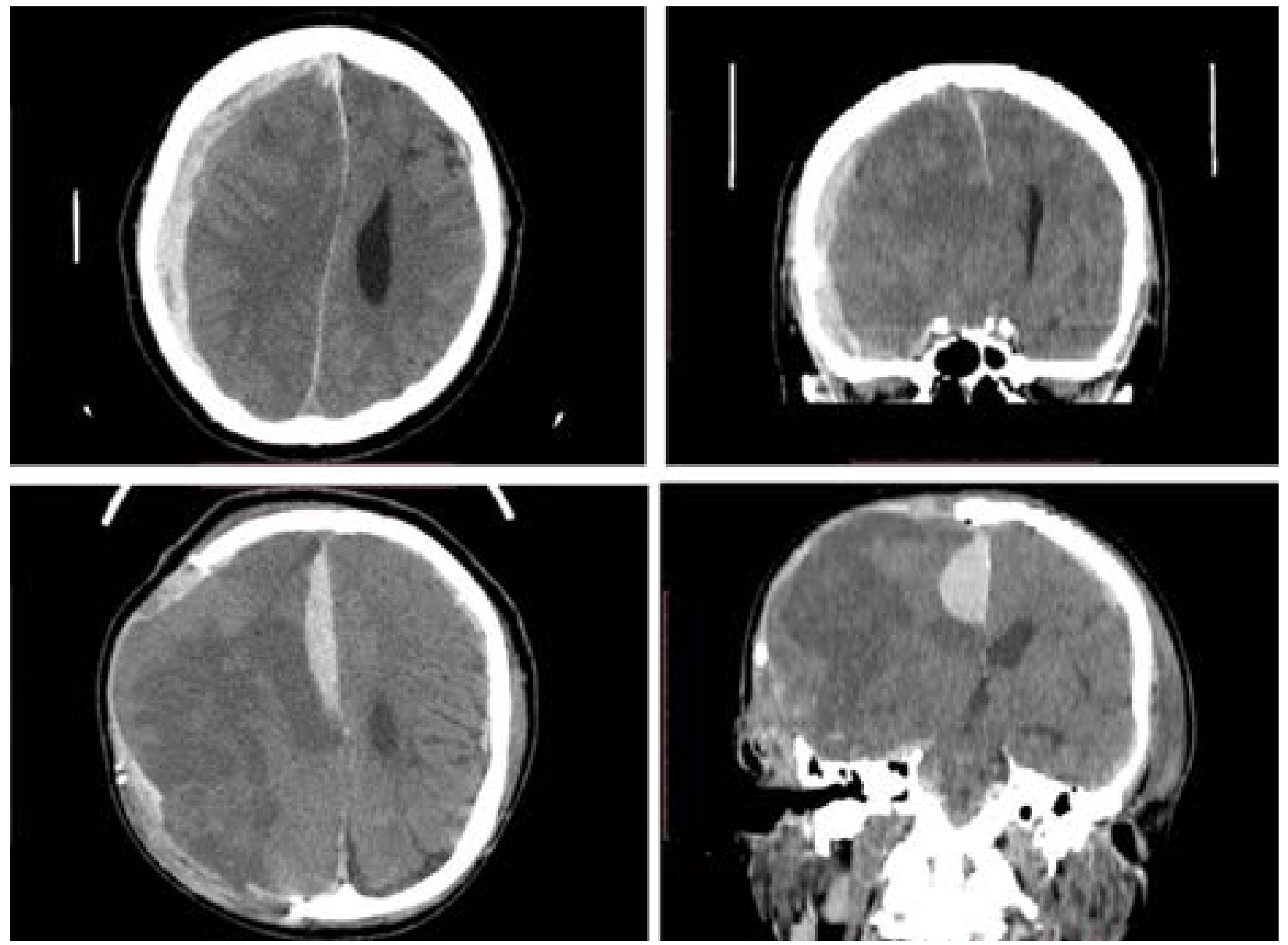

Figure 1. Post-decompressive brain displacement - computed tomography

causes here are traffic accidents and injuries experienced during physical exertion [2]. In well-developed countries, where the populations are older, the most common cause of TBI is falls [3]. Heavy TBIs are quite common in soldiers involved in warfare and in civilians who have been victims of terrorist attacks $[4,5]$. The quality of life of people who suffer from severe TBI is quite low. The remaining life expectancy of these people is two to three times shorter than for the rest of the population [6].

Additional intracranial volumes resulting from injury (haematoma, cerebral oedema) lead to raised intracranial pressure (ICP), increased ischaemia, and hypoxia of the brain. One treatment option in this group of patients is to create additional space surgically by decompressive craniectomy (DC) (Fig. 1). Performing DC can also be necessitated by the intraoperative situation when the brain tissue bulges over the dura surface. Some neurosurgeons also perform DC when brain tissue initially does not enter the intraoperative lumen, but the occurrence of such a situation in the short term after surgery is anticipated.

Extensive knowledge of the pathophysiology of TBI, unfortunately, has not translated into significantly better outcomes for patients.

\section{Aim of the study}

- To evaluate clinical outcomes after performing DC with regard to the age of patients.

- To assess the alteration in volume of both the ambient and quadrigeminal cisterns before and after DC of different sizes, with regard to the age of patients.

- To evaluate the volume of post-decompressive brain displacement (PDBD) and the largest dimension of oval craniectomy (LDOC).

\section{Material and methods}

Out of 500 consecutive patients with TBI treated surgically in the Neurosurgery Department, 45 patients were enrolled in the study (four females, 41 males, mean age 54.5 years). DC was performed on patients with a post-traumatic haematoma and/or a haemorrhagic brain contusion, both localised supratentorially and diagnosed by computed tomography (CT). After removal of a haematoma, DC was performed as a result of increased intraoperative brain volume or as a result of the high probability of postoperative raised ICP. Craniectomies with LDOC below $11 \mathrm{~cm}$ were performed for haematoma 
removal, and were not enlarged because no brain bulging was observed intraoperatively. The area of dura incision was tightly sealed using the autogenous periosteum of the skull. Plastic surgery of the dura was performed firstly to create additional space for the bulging brain tissue, secondly to provide a suitable barrier to isolate the brain, and finally to prevent postoperative CSF leakage.

In the study group, decompressive craniectomy was not a method of treating previously confirmed high ICP. The mean score according to the Glasgow Coma Scale (GCS) to qualify for surgery was 7 , with a standard deviation of 3.8. The mean time between admission to the emergency unit (EU) and the start of anaesthesia for surgery was 127 minutes, and the shortest time was 20 minutes.

Criteria for exclusion of patients from the study group were: penetrating brain injury, brain stem injury, no intracranial haematoma, extradural haematoma and posterior fossa haematoma.

Cases were analysed taking into account a division into groups depending on age and state of consciousness before performing DC. Depending on age, four groups were identified. The first group consisted of 10 patients aged 40 years or below, the second of 15 patients aged 41-55, the third of 12 patients aged 56-70, and the fourth of eight patients aged 71 or above. For these four groups, the mean GCS score before DC was respectively: 9.0, 7.0, 6.5, and 6.5 and the mortality rates were $30.0 \%, 26.7 \%, 41.2 \%$, and $75.0 \%$. Acute subdural haematoma was found in five (out of 10) patients of Group 1, 11 (out of 15) patients in Group 2, eight (out of 12) patients in Group 3, and in all eight patients in Group 4. Haemorrhagic brain contusion was diagnosed in three, three, two, and one patient respectively, and acute subdural haematoma coexisting with haemorrhagic brain contusion in two, one, two, and two patients respectively.

The DC complications were analysed in the study group. Subcutaneous haematoma following DC was found in $8.9 \%$ $(4 / 45)$ and parafalcine haematoma in $2.2 \%(1 / 45)$. Three of these five $(60 \%)$ patients required reoperation due to mass effect or neurological deterioration. The rate of superficial wound healing complications was $4.4 \%(2 / 45)$.

The control group, which was used to compare the normal volume of selected intracranial CSF cisterns with the volume of the cisterns in the study group, consisted of 50 randomised patients who had reported to EU with severe headache of unknown origin without a prior history of TBI. In these patients, computed tomography of the head and neurological examination showed no abnormalities.

Upon admission to EU, computed tomography of the head was performed to visualise intracranial traumatic changes. Clinical status was assessed using a standard neurological examination. The GCS was used to evaluate patient reactivity. Patients were subjected to standard dehydration, analgesic and anticonvulsant therapy, and perioperative antibiotic prophylaxis was initiated. Patients were operated immediately after the indications for surgery were established. On average, on the second day after DC, a control computed tomography of the head was performed. On the 14th postoperative day, patients were assessed by neurological examination and the Extended Glasgow Outcome Scale (GOSE). The results of the digital version of computed tomography of the head were used for calculations. The volume of the intracranial structures and LDOC calculations were performed using the computer programs Praezis Plus by Tatra Med, Zeppelin and Pax Station by Compart Medical Systems.

Praezis Plus was used to evaluate the PDBD volume and LDOC. For unification, the volume measurements were made in each case by means of scans from convexity of the skull to the level of foramen magnum.

Pax Station was used to evaluate the volume of the cerebrospinal fluid (CSF) in selected structures. The area corresponding to the CSF on a computed tomography image of the head was assumed to be grayscale pixels in the range of 0-18 Hounsfield units. Fluid volume calculations were performed on three head CT scans of a total thickness of $7.5 \mathrm{~mm}$. For the purpose of standardising measurements, in each case they were made $2.5-10.0 \mathrm{~mm}$ below the pineal gland. Using this method, the CSF volume in both the ambient and quadrigeminal cisterns before and after DC was calculated. The collected research material was analysed using the IBM SPSS Statistics software package.

\section{Results}

In the study group, 45 unilateral DCs were performed. The mortality rate in the study group was $40 \%$.

The relationship between the LDOC of unilateral DC and the PDBD volume consumed by the swollen brain (Fig. 2).

The smallest value of LDOC, i.e. $8.4 \mathrm{~cm}$, was associated with the formation of $25.6 \mathrm{ml}$ of PDBD. Larger craniectomies, in the LDOC range of $8-10 \mathrm{~cm}, 10-12 \mathrm{~cm}$ and $12-14 \mathrm{~cm}$,

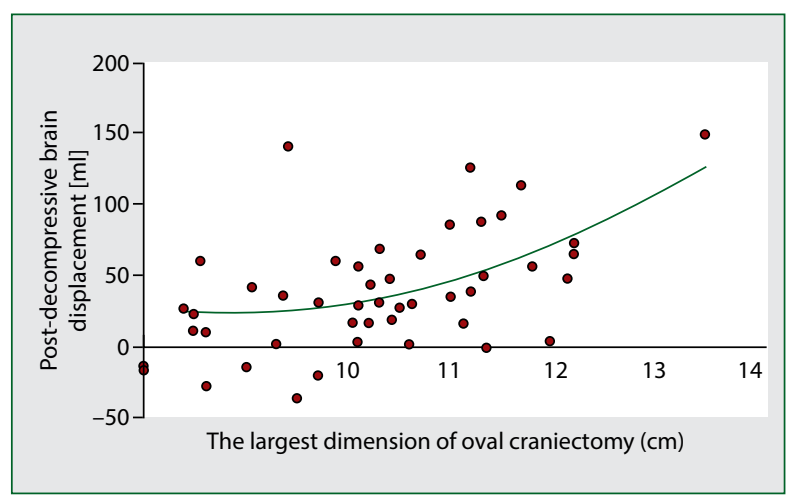

Figure 2. Post-decompressive brain displacement $(r=0.48$, $n=45)$ 
provided mean volumes of $25.9 \mathrm{ml}, 41.7 \mathrm{ml}$ and $90.6 \mathrm{ml}$ of PDBD respectively; the largest DC with an LDOC of $13.5 \mathrm{~cm}$ had a volume of $148.9 \mathrm{ml}$ of PDBD. Pearson's correlation coefficient for the examined features was $r=0.48$. The correlation was statistically significant $(\mathrm{p}<0.05)$. It is notable that, in some patients, the decompression area remained depressed after surgery; therefore PDBD values on the graph are negative.

\section{Analysis of alteration in CSF volume} of the selected basal cisterns - the ambient and quadrigeminal cistern, before and after DC

The results are shown in Table 1 and compared with the control group.

Prior to operation, the cisterns were most often clamped and their volume was about $0.5 \mathrm{ml}$, and this was three times smaller than in the control group. After surgery, the volume of the cisterns nearly doubled, reaching a mean volume of about $1 \mathrm{ml}$ (Fig. 3). This change of volume was statistically significant $(\mathrm{p}<0.001)$. The selected basal cistern volume $(\mathrm{SBCV})$ after DC

Table 1. SBCV in the test group before and after surgery and in the control group (mean, SD, p, median)

$\begin{array}{lccc} & \begin{array}{c}\text { SBCV before } \\ \text { DC } \\ (\mathbf{n}=\mathbf{4 5})\end{array} & \begin{array}{c}\text { SBCV after } \\ \mathbf{D C} \\ (\mathbf{n}=\mathbf{4 5})\end{array} & \begin{array}{c}\text { SBCV in the } \\ \text { control group } \\ (\mathbf{n}=\mathbf{5 0})\end{array} \\ \begin{array}{lccc}\text { Mean }(\mathrm{ml}) \\ \pm \text { SD }\end{array} & 0.50 \pm 0.56 & 0.98 \pm 0.66 & 1.54 \pm 0.58 \\ \mathrm{p} & & <0.001 & \\ \text { Median } & 0.33 & 0.81 & 1.48\end{array}$

was also statistically significantly different from the control group ( $\mathrm{p}<0.001$ ). In order to compare SBCV in the study group $v s$ the control group, statistical calculations using the t-test (Student's $t$-test) for independent groups were performed. The t-test for dependent (paired) groups was used to compare the SBCV in the study group before and after the DC.

Analysis of changes in the mean volume of CSF within selected basal cisterns before and after surgery in different age groups (Groups 1-4)

The t-test for dependent (paired) groups was used for statistical calculations. In Group 1, the selected basal cisterns were preoperatively clamped to the greatest extent and their mean volume was $0.32 \mathrm{ml}$. After surgery, the decompressed cisterns filled up with CSF and reached a volume of $0.84 \mathrm{ml}$, which was statistically significant $(\mathrm{p}<0.01)$ relative to the baseline values. In Groups 2, 3 and 4, there was also a significant postoperative increase in SBCV $(\mathrm{p}<0.001, \mathrm{p}<0.001$, and $\mathrm{p}<0.01$, respectively). All results are shown in Table 2 .

An age-specific analysis of the early effects

of the applied treatment and an assessment of the neurological condition of patients 14 days after surgery (Groups 1-4)

The best outcomes evaluated on the $14^{\text {th }}$ day after surgery were those in Group 1. Very good or good condition of the patients was found in 70\% (GOSE $=7$ or GOSE $=8)$, while death was reported in $30 \%$ of the patients $($ GOSE $=1)$. In Group 2, the results of the evaluation were respectively GOSE $=7$ or GOSE $=8$ in $53 \%$ of the patients and GOSE $=1$ in $27 \%$ of the patients. In Group 3, GOSE $=7$ or GOSE $=8$ in 33\% of

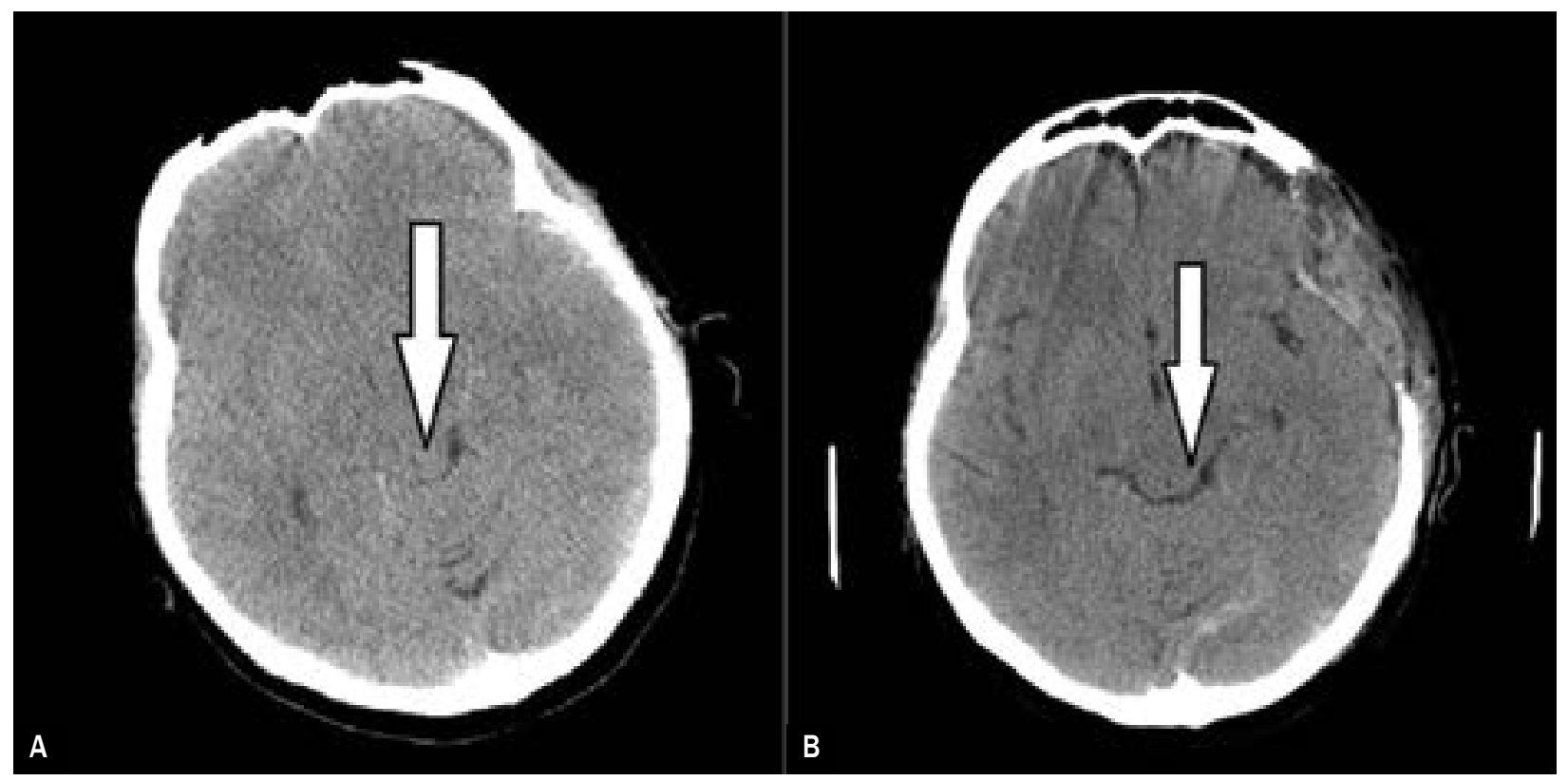

Figure 3. Selected basal cistern volume before and after decompressive craniectomy - computed tomography 


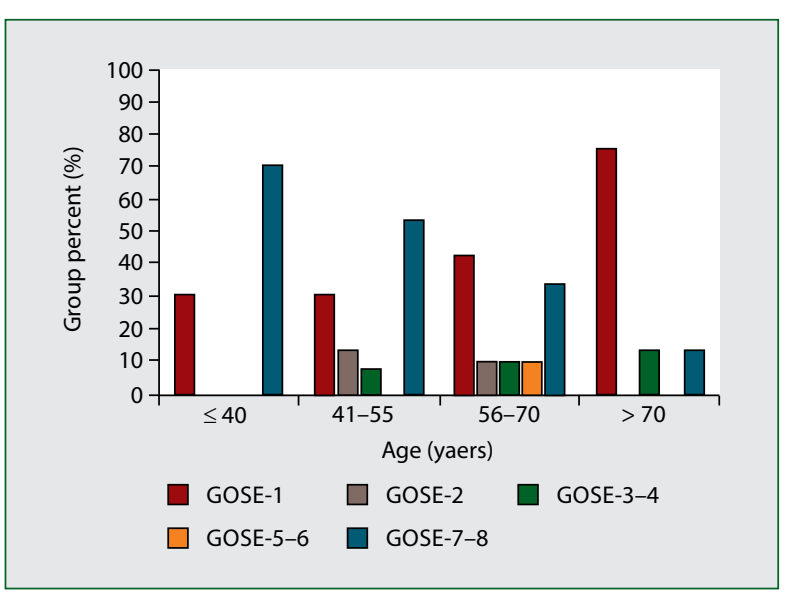

Figure 4. Clinical state of patients on the $14^{\text {th }}$ day after DC in different age groups according to the GOSE scale $(n=45$, $\rho 45=-0.407)$

the patients and GOSE $=1$ in $42 \%$ of the patients. In Group 4 , very good or good condition of the patients (GOSE $=7$ or GOSE $=8$ ) was found only in $12.5 \%$ of the patients while $75 \%$ of the patients died (GOSE $=1$ ). The results of the above analysis are shown in Figure 4.

The Spearman rho correlation coefficient ( $\rho$ Spearman) showed a statistically significant negative correlation between age and the clinical state of patients evaluated with the GOSE scale 14 days after surgery (with increase in age, GOSE score decreased, $\rho 45=-0.407, \mathrm{p}<0.01$ ).

The correlations between pre- and postoperative SBCV and the volume of the PDBD and neurological condition of patients on the 14th day after surgery were estimated. There was no statistically significant correlation between SBCV and the neurological status of patients on the 14th postoperative day or between PDBD and the status of patients evaluated on the GOSE scale (Fig. 5). The only statistically significant correlation was found for the relationship between postoperative SBCV and the status of patients evaluated according to the GOSE scale on the 14th day after surgery in the age group up to 40 years $(r=0.623, p<0.05)$. Pearson's correlation coefficient was used for calculations.

\section{Discussion}

This study presents volume changes of selected intracranial fluid spaces prior to and after DC, and the usefulness of PDBD space in patients after TBI. These parameters have been linked to the clinical state of patients 14 days after surgery, also taking into consideration their preoperative neurological condition and age. There have only been a few published studies concerning changes in the volume of the brain, herniating above the skull surface in TBI patients after DC. Single publications have reported that PDBD may be a good prognostic factor and that the decompression effect

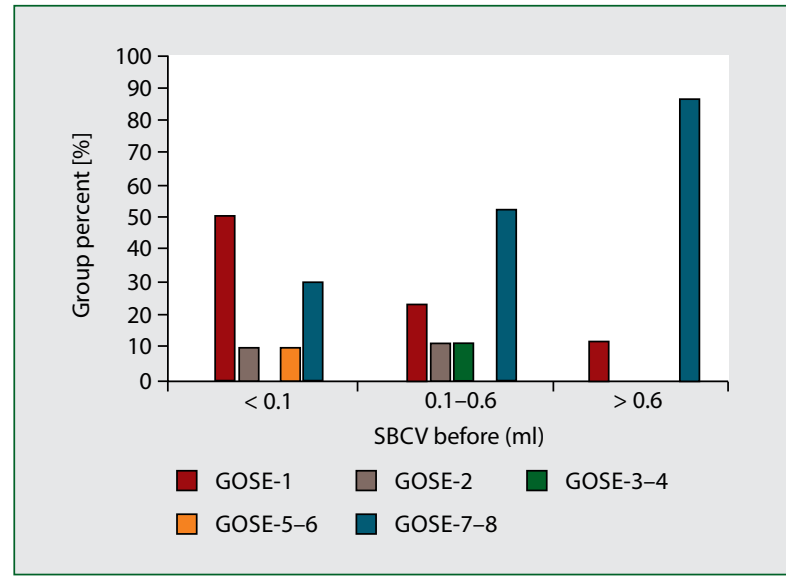

Figure 5. SBCV before DC and the clinical state of patients on the $14^{\text {th }}$ postoperative day according to the GOSE scale $(n=45$, $\rho 45=0.224, p=0.122$ )

can be evaluated by measuring PDBD volume $[7,8]$. However, this was not definitely confirmed in our current study. Severe traumatic brain injury has a poor prognosis regardless of the treatment method used. Evaluation of the volume change of the CSF cisterns before and after DC has also been rarely presented in the literature. No publication has been found on this subject concerning patients operated due to intracranial haematoma. The only text evaluating the volume of the basal CSF cisterns in patients after head injury is the study by Głowacki et al. [9]. The authors found that selected basal cisterns significantly reduce their volume after TBI, which was also confirmed in our current study. Based on the results of many publications, it is known that DC immediately, and in the long term, decreases ICP in a statistically significant way. It should also be noted that a reduction of the ICP is associated with an enlargement of the CSF space, but this does not mean an improvement of the neurological condition in every patient. The coefficient of correlation between preoperative cistern volume and the condition of patients on the 14th day after surgery was rather low for the whole study group. However, in our study we found that the volume of intracranial CSF cisterns increased significantly after DC in each age group. Therefore, this may be a good indicator of intracranial tightness.

The use of DC for the treatment of head injuries has a long history, but it remains controversial. Previous research has shown that DC results in lower ICP and increases cerebral perfusion pressure (CPP) [10-14]. However, there are many conflicting findings in the literature concerning treatment results. Some authors have reported good outcomes in less than $20 \%$ of patients [15], while others have reported good outcomes in more than $70 \%$ [16]. Further research should define the optimum criteria for decompressive craniectomy. However, it should be noted that too small a bone window, with LDOC less than $12 \mathrm{~cm}$, has been confirmed to increase 
Table 2. SBCV before and after DC in relation to age (mean, SD, p)

\begin{tabular}{|c|c|c|c|c|c|c|c|c|}
\hline Group & \multicolumn{2}{|c|}{$1(n=10)$} & \multicolumn{2}{|c|}{$2(n=15)$} & \multicolumn{2}{|c|}{$3(n=12)$} & \multicolumn{2}{|c|}{$4(n=8)$} \\
\hline Age (in years) & \multicolumn{2}{|c|}{ up to 40} & \multicolumn{2}{|c|}{$41-55$} & \multicolumn{2}{|c|}{$56-70$} & \multicolumn{2}{|c|}{$71+$} \\
\hline \multirow[t]{2}{*}{$\mathrm{SBCV}($ mean $(\mathrm{ml}) \pm \mathrm{SD})$} & before DC & after DC & before DC & after DC & before DC & after DC & before DC & after DC \\
\hline & $0.32 \pm 0.24$ & $0.84 \pm 0.63$ & $0.55 \pm 0.73$ & $0.90 \pm 0.75$ & $0.32 \pm 0.24$ & $0.84 \pm 0.63$ & $0.55 \pm 0.73$ & $0.90 \pm 0.75$ \\
\hline$p$ & \multicolumn{2}{|c|}{$<0.01$} & \multicolumn{2}{|c|}{$<0.001$} & \multicolumn{2}{|c|}{$<0.001$} & \multicolumn{2}{|c|}{$<0.01$} \\
\hline
\end{tabular}

the chance of brain injury and poor outcome [17]. As yet, there are no clear guidelines for treating TBI. In everyday clinical practice, the benefits of DC must be thoroughly weighed against the risks. The long-term outcome of DC in TBI patients is not fully understood and it is difficult to interpret due to a variety of factors that may influence the condition of patients. Identification of these factors can improve treatment methods and life quality of head injury patients $[10,18-23]$. Severe TBI is usually associated with a poor prognosis [14, 24-27]. Outcomes of DC have been described by some authors $[28,29]$, but the available studies were not randomised and were mostly based on small patient groups limited to individual centres. In this context, of particular interest are the results of RESCUE-ASDH - a multi-centre, pragmatic, parallel group randomised trial conducted by A. G. Kolias from the University of Cambridge's Department of Clinical Neurosciences. RESCUE-ASDH aimed to compare the clinical and cost-effectiveness of decompressive craniectomy versus craniotomy for the management of adult patients with head injuries undergoing evacuation of an acute subdural haematoma (ASDH).

While the DC procedure is technically straightforward, according to the literature it exposes a patient to risk complications which can negatively impact outcome. Such complications can be divided into three groups: a) haemorrhagic (postoperative haematoma, recurrent ipsilateral haematoma, contralateral haematoma, haemorrhagic transformation of brain contusion or ischaemic area), b) infectious/inflammatory (wound healing complications, meningitis and ventriculitis, abscess formation and epidural/subdural empyema), and c) CSF compartment disorders (hydrocephalus, subdural hygroma or CSF leak/fistula formation). Other complications of DC are syndrome of the trephined, paradoxical herniation, and falls on an unprotected cranium [30].

It should be remembered that in DC patients further cranioplasty is required in the future which may also be associated with complications similar to those found in DC, although some complications are characteristic for cranioplasty e.g. bone flap resorption/depression and cosmetic defects [30].

In our study, however, we did not find that DC complications were frequent and the procedure was not very risky, although it does not protect against all common risk of injury. It should be remembered that some of the above-mentioned situations (haemorrhagic transformation of brain contusion or ischaemic area, hydrocephalus, meningitis and ventriculitis, abscess formation and epidural/ subdural empyema, especially in the case of penetrating injuries) can be a natural consequence of TBI, and can occur without surgery.

To summarise, despite the method limitations, decompressive craniectomy is a valuable treatment option for traumatic brain injury (TBI) management. That it helps to reduce post-traumatic intracranial volume disorders was confirmed in this study and this is in agreement with the results of other studies. However, the study group was heterogeneous and some factors could have influenced the final study results (e.g. patient age diversity, different initial neurological status, additional physician load). Moreover, even promptly performed DC remains an ineffective procedure in patients with very severe brain damage, which itself leads to a poor prognosis, regardless of the method of treatment.

DC is considered to be an effective method in selected post-traumatic cases in combination with conservative pharmacological treatment. Qualifications for operations should be determined on a case-by-case basis.

\section{Conclusions}

A statistically significant increase in the volume of preoperatively clamped intracranial CSF cisterns was observed in each age group after DC.

DC increases the volume reserve for the enlarged post-traumatic brain depending on the size of the removed skull vault.

The best early results of TBI management using DC were obtained in patients under the age of 55 . It has limited effectiveness in the over 70 years old group.

If herniation of the brain tissues follows haematoma removal, the LDOC should be enlarged to a diameter of more than $12 \mathrm{~cm}$. DC should be as large as possible, and the limits of its dimensions should be the limits of anatomical safety.

In every patient with clamped basal cisterns, a skin incision enabling appropriate LDOC should be planned before surgery.

Conflict of Interest: The authors declare that they have no conflict of interest.

Ethical approval: The local bioethics committee approved the research project upon which this study was based. 


\section{References}

1. Fearnside MR, Simpson DA. Epidemiology. In: Reilly P, Bullock R (ed) Head Injury. Pathophysiology and management of severe closed injury. Chapman and Hall Medical, London. 1997: 3-24.

2. Maas AIR, Stocchetti N, Bullock R. Moderate and severe traumatic brain injury in adults. Lancet Neurol. 2008; 7(8): 728-741, doi: 10.1016/S1474-4422(08)70164-9, indexed in Pubmed: 18635021.

3. Faul M, Wald M, Wu L, et al. Traumatic brain injury in the United States: emergency department visits, hospitalizations, and deaths, 2002-2006. 2010, doi: 10.15620/cdc.5571.

4. Ling G, Bandak F, Armonda R, et al. Explosive blast neurotrauma. J Neurotrauma. 2009; 26(6): 815-825, doi: 10.1089/neu.2007.0484, indexed in Pubmed: 19397423.

5. Roberts SAG, Toman E, Belli A, et al. Decompressive craniectomy and cranioplasty: experience and outcomes in deployed UK military personnel. Br J Neurosurg. 2016; 30(5): 529-535, doi: 10.1080/02688697.2016.1208807, indexed in Pubmed: 27437912.

6. Baguley IJ, Nott MT, Howle AA, et al. Late mortality after severe traumatic brain injury in New South Wales: a multicentre study. Med J Aust. 2012; 196(1): 40-45, indexed in Pubmed: 22256933.

7. Xiao F, Chiang IJ, Hsieh TMH, et al. Estimating postoperative skull defect volume from CT images using the ABC method. Clin Neurol Neurosurg. 2012; 114(3): 205-210, doi: 10.1016/j.clineuro.2011.10.003, indexed in Pubmed: 22035646.

8. Wirtz CR, Steiner T, Aschoff A, et al. Hemicraniectomy with dural augmentation in medically uncontrollable hemispheric infarction. Neurosurg Focus. 1997; 2(5): E3; discussion 1 p following E3, indexed in Pubmed: 15096004.

9. Glowacki M, Budohoski K, Marszalek P, et al. A non-invasive assessment of intracranial volume reserve by measuring cerebrospinal fluid volume with the aid of CT imaging. Acta Neurochir Suppl. 2010; 106: 199-202, doi: 10.1007/978-3-211-98811-4_37, indexed in Pubmed: 19812949.

10. Bohman LE, Schuster JM. Decompressive craniectomy for management of traumatic brain injury: an update. Curr Neurol Neurosci Rep. 2013; 13(11): 392, doi: 10.1007/s11910-013-0392-x, indexed in Pubmed: 24101348.

11. Cooper DJ, Rosenfeld JV, Wolfe R, et al. DECRA Trial Investigators, Australian and New Zealand Intensive Care Society Clinical Trials Group. Decompressive craniectomy in diffuse traumatic brain injury. N Engl J Med. 2011; 364(16): 1493-1502, doi: 10.1056/NEJMoa1102077, indexed in Pubmed: 21434843.

12. Chesnut R, Temkin N, Carney N, et al. A Trial of Intracranial-Pressure Monitoring in Traumatic Brain Injury. New England Journal of Medicine. 2012; 367(26): 2471-2481, doi: 10.1056/nejmoa1207363.

13. Kolias AG, Adams H, Timofeev I, et al. Decompressive craniectomy following traumatic brain injury: developing the evidence base. Br J Neurosurg. 2016; 30(2): 246-250, doi: 10.3109/02688697.2016.1159655, indexed in Pubmed: 26972805.

14. Hutchinson PJ, Kolias AG, Timofeev IS, et al. RESCUEicp Trial Collaborators. Trial of Decompressive Craniectomy for Traumatic Intracranial Hypertension. N Engl J Med. 2016; 375(12): 1119-1130, doi: 10.1056/NEJMoa1605215, indexed in Pubmed: 27602507.

15. Albanèse J, Leone M, Alliez JR, et al. Decompressive craniectomy for severe traumatic brain injury: Evaluation of the effects at one year. Crit Care Med. 2003; 31(10): 2535-2538, doi: 10.1097/01. CCM.0000089927.67396.F3, indexed in Pubmed: 14530763.
16. Olivecrona M, Rodling-Wahlström M, Naredi S, et al. Effective ICP reduction by decompressive craniectomy in patients with severe traumatic brain injury treated by an ICP-targeted therapy. J Neurotrauma. 2007; 24(6): 927-935, doi: 10.1089/neu.2005.356E, indexed in Pubmed: 17600510.

17. Wagner S, Schnippering $H$, Aschoff A, et al. Suboptimum hemicraniectomy as a cause of additional cerebral lesions in patients with malignant infarction of the middle cerebral artery. J Neurosurg. 2001; 94(5): 693-696, doi: 10.3171/jns.2001.94.5.0693, indexed in Pubmed: 11354398.

18. Kolias AG, Kirkpatrick PJ, Hutchinson PJ. Decompressive craniectomy: past, present and future. Nat Rev Neurol. 2013; 9(7): 405-415, doi: 10.1038/nrneurol.2013.106, indexed in Pubmed: 23752906.

19. Perel P, Arango M, Clayton T, et al. MRC CRASH Trial Collaborators. Predicting outcome after traumatic brain injury: practical prognostic models based on large cohort of international patients. BMJ. 2008; 336(7641): 425-429, doi: 10.1136/bmj.39461.643438.25, indexed in Pubmed: 18270239.

20. Duhaime AC, Gean AD, Haacke EM, et al. Common Data Elements Neuroimaging Working Group Members, Pediatric Working Group Members. Common data elements in radiologic imaging of traumatic brain injury. J Magn Reson Imaging. 2010; 32(3): 516-543, doi: 10.1002/jmri.22259, indexed in Pubmed: 20815050.

21. Steyerberg EW, Mushkudiani N, Perel P, et al. Predicting outcome after traumatic brain injury: development and international validation of prognostic scores based on admission characteristics. PLoS Med. 2008; 5(8): e165; discussion e165, doi: 10.1371/journal. pmed.0050165, indexed in Pubmed: 18684008.

22. Mushkudiani NA, Engel DC, Steyerberg EW, et al. Prognostic value of demographic characteristics in traumatic brain injury: results from the IMPACT study. J Neurotrauma. 2007; 24(2): 259-269, doi: 10.1089/ neu.2006.0028, indexed in Pubmed: 17375990.

23. Marshall LF, Marshall SB, Klauber MR, et al. The diagnosis of head injury requires a classification based on computed axial tomography. J Neurotrauma. 1992; 9(5): 287-92.

24. Honeybul S, Ho KM, Lind CRP, et al. Decompressive craniectomy for diffuse cerebral swelling after trauma: long-term outcome and ethical considerations. J Trauma. 2011; 71(1): 128-132, doi: 10.1097/ TA.0b013e3182117b6c, indexed in Pubmed: 21460742.

25. Thomsen IV. Late psychosocial outcome in severe traumatic brain injury. Preliminary results of a third follow-up study after 20 years. Scand J Rehabil Med Suppl. 1992; 26: 142-152, indexed in Pubmed: 1488637.

26. Grauwmeijer E, Heijenbrok-Kal MH, Haitsma IK, et al. Employment Outcome Ten Years after Moderate to Severe Traumatic Brain Injury: A Prospective Cohort Study. J Neurotrauma. 2017; 34(17): 2575-2581, doi: 10.1089/neu.2016.4846, indexed in Pubmed: 28447873.

27. Turgeon AF, Lauzier F, Zarychanski R, et al. TBI-Prognosis Study Team and the Canadian Critical Care Trials Group. Prognostication in critically ill patients with severe traumatic brain injury: the TBI-Prognosis multicentre feasibility study. BMJ Open. 2017; 7(4): e013779, doi: 10.1136/bmjopen-2016-013779, indexed in Pubmed: 28416497.

28. Park JH, Park JE, Kim SH, et al. Outcomes of Ultra-Early Decompressive Craniectomy after Severe Traumatic Brain Injury - Treatment Outco- 
mes after Severe TBI. Korean J Neurotrauma. 2014; 10(2): 112-118, doi: 10.13004/kjnt.2014.10.2.112, indexed in Pubmed: 27169044.

29. Rubiano AM, Villarreal W, Hakim EJ, et al. Early decompressive craniectomy for neurotrauma: an institutional experience. Ulus Travma Acil Cerrahi Derg. 2009; 15(1): 28-38, indexed in Pubmed: 19130336.
30. Kurland DB, Khaladj-Ghom A, Stokum JA, et al. Complications Associated with Decompressive Craniectomy: A Systematic Review. Neurocrit Care. 2015; 23(2): 292-304, doi: 10.1007/s12028-015-0144-7, indexed in Pubmed: 26032808. 